\title{
EDITORIAL
}

\section{Theophylline and phosphodiesterase inhibitors}

\author{
M. Aubier*, P.J. Barnes**
}

This issue of the European Respiratory Journal starts a series of short reviews based on a Satellite Meeting held during the European Respiratory Society Annual Meeting in Nice in October 1994. The symposium was supported by Byk Gulden (Germany) and brought together experts who discussed new data on the immunomodulatory action of theophylline, and also looked at future developments with more selective phosphodiesterase (PDE) inhibitors.

Theophylline has been used for more than $50 \mathrm{yrs}$ in the treatment of asthma. The proposed clinical effects of theophylline are bronchial smooth muscle relaxation, improved mucociliary clearance, increased efficiency of diaphragmatic contraction, decreased pulmonary artery pressure, and central respiratory stimulation. It is now increasingly recognized that, besides these classical clinical properties, theophylline and more selective PDE inhibitors have anti-inflammatory and immunomodulatory effects. Indeed several studies have demonstrated that, in vitro, xanthines have a nonspecific suppressor activity in human peripheral lymphocytes [1], inhibit eosinophil degranulation [2], inhibit histamine release from mast cells and basophils [3], and have a direct inhibitory action on human alveolar respiratory burst [4]. These anti-inflammatory and immunomodulatory effects of xanthines have also been observed in vivo in animal models and also in humans. In the guinea-pig, it has been shown that xanthines attenuate airway hyperresponsiveness [5] and the late response in sensitized animals [6]. They also inhibit eosinophil infiltration into guinea-pig airways [7].

In humans, xanthines also inhibit the late asthmatic response [8], and reduce neutrophil and eosinophil activation in airways, to an extent comparable to the effect of low dose inhaled steroids ( $0.4 \mathrm{mg}$ budesonide daily) [9]. Finally, theophylline withdrawal causes a worsening of clinical asthma, even in patients already receiving high dose inhaled steroids $[10,11]$. This is associated with a fall in activated T-lymphocytes in the blood, and a rise in these cells in the airway mucosa, suggesting that theophylline may regulate the trafficking of activated lymphocytes into the airways. The target cell for theophylline action may, therefore, be either T-cells or bronchial vascular endothelial cells that regulate lymphocyte migration [11].

Correspondence: *Inserm U408, Unité de Pneumologie de l'Hôpital Bichat, Paris, France. $* *$ and Dept of Thoracic Medicine, National Heart and Lung Institute, London, UK.
Interestingly, in some studies, these anti-inflammatory and immunomodulatory effects of theophylline have been observed at rather lower plasma concentrations than those considered to be required for bronchodilatation. This has suggested that theophylline might be used for the maintenance treatment of asthma at lower doses, rather than aiming for plasma concentrations of 10-20 $\mathrm{mg} \cdot l^{-1}$ that were determined as a compromise between the bronchodilatory effect of theophylline and side-effects. It may be more useful to aim for plasma concentrations of $5-10 \mathrm{mg} \cdot l^{-1}$, as this would preserve the immunomodulatory effect but avoid the side-effects that limit its usefulness [12].

Although theophylline is known to be a nonselective inhibitor of PDEs, it is not certain whether its anti-asthma actions can be entirely explained by this mechanism. The therapeutic plasma concentrations of theophylline are in the range $25-100 \mu \mathrm{M}$, when there is relatively little inhibition of PDE activity. At present, there is no evidence of selectivity of theophylline for any of the PDE isoenzyme families, although it remains a possibility that unique PDE isoenzymes may be discovered that are more sensitive to theophylline. It is also possible that certain PDE isoenzymes are induced in asthmatic airways, and this may increase the sensitivity of asthmatic cells to inhibition by theophylline. Whilst some of the actions of theophylline may be due to PDE inhibition, it is likely that there are other molecular mechanisms of action, and this area deserves further study. Nevertheless, the interest in PDEs prompted by the pharmacology of theophylline has led to an enormous interest in PDE isoenzymes, and much new information about PDE isoenzymes in the airways is discussed in this series of reviews. This will undoubtedly result in new therapeutic agents for the treatment of asthma in the future, particularly if the problem of side-effects can be overcome.

Theophylline remains a very useful treatment for asthma, particularly in patients with severe disease. The demonstration that it may have immunomodulatory or anti-inflammatory effects, even at low plasma concentrations, has posed the question of how theophylline should be placed in the guidelines for asthma treatment in the future. At present, most guidelines recommend that theophylline is added after high dose inhaled steroids (1.5-2 mg daily). It is probable that theophylline exerts its anti-asthma effects via different molecular mechanisms from glucocorticoids, and there are theoretical reasons to believe that there may be a synergistic interaction between these two classes of drug. The 
steroid-sparing effects of theophylline have long been recognized [13], and recent studies have documented that theophylline gives comparable control of asthma to an inhaled glucocorticoid (beclomethasone dipropionate, 0.4 mg daily) in children with mild to moderate asthma [14]. This suggests that theophylline may be used in combination with inhaled steroids to control asthma, without the need to increase the dose of inhaled steroids when symptoms are not controlled at doses of $0.4-0.8 \mathrm{mg}$ daily. Controlled trials are currently in progress to explore this possibility. The fact that theophylline is active orally and may be given once or twice daily may help to increase compliance [15]. In the future, it is possible that theophylline will be introduced even earlier in management, at a stage which precedes the use of inhaled steroids, but carefully controlled clinical trials will be needed before this can be recommended.

In response to the new information about theophylline that is discussed in detail in this series of reviews, its role in the management of asthma should now be reevaluated. Future clinical studies in chronic asthma are required to evaluate the anti-inflammatory and immunomodulatory effects of more selective PDE inhibitors, particularly PDE IV inhibitors, to determine whether the encouraging in vitro and in vivo animal studies can be extrapolated to the clinical situation.

\section{References}

1. Zocchi MR, Pardi R, Gromo G, et al. Theophylline induces nonspecific supressor activity in human peripheral blood lymphocytes. J Immunopharmacol 1985; 7 : 217-234.

2. Yukawa T, Kroegel C, Chanez P, et al. Effect of theophylline and adenosine on eosinophil function. Am Rev Respir Dis 1989; 140: 327-333.

3. Louis RE, Radermecker MR. Substance P induced histamine release from human basophils, skin and lung fragments: effect of nedocromil sodium and theophylline. Int Arch Allergy Appl Immunol 1990; 92: 329-333.

4. Dent G, Giembycz MA, Rabe KF, Wolf B, Barnes PJ,
Magnussen H. Theophylline suppresses human alveolar macrophage respiratory burst through phosphodiesterase inhibition. Am J Respir Cell Mol Biol 1994; 10: 565572.

5. Tarayre JP, Aliaga M, Barbera M, Tisseyre N, Vieu S, Tisne-Versailles J. Pharmacological modulation of a model of bronchial inflammation after aerosol-induced active anaphylactic shock in conscious guinea-pigs. $J$ Immunopharmacol 1991; 13: 349-356.

6. Banyard RE, Clay TP, Reynolds NJ, Wong A. Oral drug therapy in the guinea-pig asthma model. Eur J Pharmacol 1990; 183: 2121-2128.

7. Sanjar S, Aoki S, Kristersson A, Smith D, Morley J. Antigen challenge induces pulmonary airway eosinophil accumulation and airway hyperreactivity in sensitized guinea-pigs: the effect of anti-asthma drugs. Br J Pharmacol 1990; 99: 679-689.

8. Ward AJM, McKenniff M, Evans JM, Page CP, Costello JF. Theophylline - an immunodulatory role in asthma? Am Rev Respir Dis 1993; 147: 518-523.

9. Venge P, Dahl R, Karlstrom R, Pedessen B, Peterson CGB. Eosinophil and neutrophil activity in asthma in a one year double-blind trial with theophylline and two doses of inhaled budesonide. J Allergy Clin Immunol 1993; 89: 141.

10. Brenner MR, Berkowitz R, Marshall N, Strunk RC. Need for theophylline in severe steroid-requiring asthmatics. Clin Allergy 1988; 18: 143-150.

11. Kidney J, Dominguez M, Taylor PM, Rose M, Chung $\mathrm{KF}$, Barnes PJ. Immunomodulation by theophylline in asthma: demonstration by withdrawal of therapy. Am J Respir Crit Care Med 1995; (in press).

12. Barnes PJ, Pauwels RA. Theophylline in asthma: time for reappraisal? Eur Respir J 1994; 7: 579-591.

13. Nassif EG, Weinburger M, Thompson R, Huntley W. The value of maintenance theophylline in steroid-dependent asthma. N Engl J Med 1981; 304: 71-75.

14. Tinkelman DG, Reed CE, Nelson HS, Offord KP. Aerosol beclomethasone dipropionate compared with theophylline as primary treatment of chronic, mild to moderately severe asthma in children. Pediatr 1993; 92: 64-77.

15. Kelloway JS, Wyatt RA, Adlis SA. Comparison of patients' compliance with prescribed oral and inhaled asthma medications. Arch Intern Med 1994; 154: 1349 1352. 